\title{
Students' perceptions of the impact of video lectures with embedded quiz questions on e-learning in dentistry
}

\author{
Won-Pyo Lee ${ }^{1}$ and Joo-Hun Song ${ }^{2 *}$ \\ ${ }^{1}$ Assistant Professor, Department of Periodontology, School of Dentistry, Chosun University, Gwangju, Republic of Korea \\ ${ }^{2}$ Assistant Professor, Department of Prosthodontics, School of Dentistry, Chosun University, Gwangju, Republic of Korea
}

During the COVID-19 pandemic, e-learning has become more prevalent in dental education. In this study, we investigated the effectiveness of video lectures with embedded quiz questions. A questionnaire survey was conducted on the preferences of each educational method for dental students $(n=70)$ who took all three lecture types (offline lecture, Group 1; video lecture without embedded quiz, Group 2; and video lecture with embedded quiz, Group 3). In terms of other behaviors that imply the nonacademicrelated activities, Group 2 was significantly the highest, whereas in terms of lecture flow, it was the lowest. In terms of learning motivation and learning confidence, Group 3 lecture type was significantly preferred. In terms of communication with professor and communication with students, Group 1 was the most preferred, but there was no significant difference compared with Group 3. In terms of overall lecture satisfaction, Group 3 lecture type was significantly the highest. The e-learning method using video lectures with embedded quiz questions could be an effective alternative to traditional offline lectures in dental education.

Key Words: Dental students; Embedded questions; Online lectures; Quiz; Video

(c) This is an open-access article distributed under the terms of the Creative Commons Attribution Non-Commercial License (http://creativecommons.org/licenses/by-nc/4.0) which permits unrestricted noncommercial use, distribution, and reproduction in any medium, provided the original work is properly cited.

\section{Introduction}

전 세계적으로 대규모로 빠르게 확산된 2019년 코로나바이 러스(COVID-19) 대유행 상황은 교육을 포함한 많은 분야에 변 화를 일으켰다[1]. 유네스코의 2020년 최근 보고서에 따르면 120 개 이상의 국가가 보건 당국의 조언에 따라 교육 기관을 폐 쇄했고, 캠퍼스에서 체육 수업을 중단했다고 한다. 이에 따라, 거의 모든 국가에서 교육 프로그램을 비대면 온라인 교육으로 전환했다[2]. COVID-19 대유행 기간 동안 교수들은 교육 과정 의 빠른 변화에 신속하게 적응해야 했고, 학생들에게 필수 교육 및 학습 활동을 제공하기 위해 온라인 플랫폼에 전적으로 의존
해야 했다. 비대면 온라인 교육으로의 빠른 전환은 COVID-19 대유행 기간 동안 학습 연속성을 보장하기 위해 불가피한 조치 였지만, 교수 및 학생 양쪽에게 여러 어려움을 안겨주었다. 학습 자의 동기 부족, 원격 온라인 학습 방법에 대한 적응의 어려움, 기술 및 서버 대역폭 문제, 강의를 위한 온라인 학습 콘텐츠 생 성 등이 이에 해당된다[3,4].

다양한 비대면 온라인 교육 형태 중, 교수가 사전 녹화한 동영 상 강의를 특정 온라인 플랫폼을 통해 학생들에게 제공하는 비 동시적 온라인 수업이 가장 일반적인 방식이다[5]. 이 방식은 학 생들에게 시간과 공간의 제약 없이 자율적으로 반복적인 학습 을 가능케 한다. 하지만, 이러한 자율성으로 학생의 학습의지가

Received February 23, 2021; Revised April 7, 2021; Accepted April 10, 2021

${ }^{*}$ Corresponding author: Joo-Hun Song, Department of Prosthodontics, School of Dentistry, Chosun University, 303 Pilmun-daero, Dong-gu, Gwangju 61452, Republic of Korea.

Tel: +82-62-220-3820, Fax: +82-62-227-7811, E-mail: jhun2020@chosun.ac.kr 
부족할 경우 학습 효과가 떨어지는 한계는 갖는다[6]. 즉, 온라 인 출석 체크를 위해 사전 녹화된 동영상 강의를 틀어만 놓고, 딴짓(other behaviors)을 하여도 교수가 모니터링 및 제어할 방 법이 없다[7]. 이러한 학습의지의 차이는 비동시적 온라인 수업 방식에서 학생 간 학습격차를 발생시키며, 결국 학생들의 학업 성취도에 부정적인 요인으로 작용한다[8].

이러한 학생 간 학습격차를 줄일 수 있는 대표적인 방법으로 수업 시간 중 학생들에게 제시하는 간단한 퀴즈를 들 수 있다. 최근 보고된 Sotola와 Crede [9]의 52개 수업에서 총 8,000여명 의 학생을 대상으로 한 연구자료들을 메타분석한 연구에서, 수 업 시간 중에 퀴즈 문제를 자주 제시하는 것이 학생들의 학습격 차를 줄이고 학업성적 향상에 긍정적으로 작용한다는 것을 보 고하였다. 또한, 이러한 효과는 온라인 또는 서면상의 퀴즈 형태 와는 상관없이 모두 긍정적인 결과를 갖는다고 하였다.

따라서, 이번 연구에서는 치과대학 학생들을 대상으로 한 설 문을 통해, 퀴즈 삽입형 동영상 강의를 활용한 비동시적 온라인 수업 방식이 전통적인 대면 수업 및 일반적인 비동시적 온라인 수업 방식과 비교하여 효과적인 교육방법인지 평가하고자 하였 다.

\section{Materials and Methods}

\section{연구대상}

이번 연구는 조선대학교 치과대학 본과 2학년 2학기부터 본 과 3학년 2학기까지 특정 치주과 교수 1인(이원표 교수) 치주과 학 수업을 모두 수강하였으며, 사전에 연구목적을 설명한 후 연 구참여에 동의한 총 70 명 학생(남자 50명, 여자 20명)을 설문대 상으로 하였다.

\section{강의진행 방식}

각 학기 별 치주과학 진행방식은 다음과 같았으며, 각 학기 별 치주과학 수업 내용은 달랐다.

\section{본과 2학년 2학기 치주과학 수업(2019년 2학기)}

전통적인 대면 수업(offline lecture).

\section{본과 3학년 1학기 치주과학 수업(2020년 1학기)}

조선대학교 자체 학습관리시스템(learning management system, LMS)인 E-Class 플랫폼을 통한 퀴즈 삽입이 없는 일반 적인 동영상 강의를 활용한 비동시적 온라인 수업(video lecture without embedded quiz).

\section{본과 3학년 2학기 치주과학 수업(2020년 2학기)}

구글 클래스룸(Google classroom) 플랫폼을 통한 퀴즈 삽입 형 동영상 강의를 활용한 비동시적 온라인 수업(video lecture with embedded quiz).

\section{퀴즈 삽입형 동영상 강의 제작 및 진행}

교수자는 구글 클래스룸(https://classroom.google.com)과 연동되며 무료 웹 어플리케이션인 Edpuzzle (https://edpuzzle. $\mathrm{com})$ 을 사용하였다. 먼저, 사전 녹화된 일반적인 형태의 동영 상 강의를 가급적 15 분에서 20 분 정도 분량의 수업으로 나누어 Edpuzzle 사이트에 업로드하였다. 이후, 상기 어플리케이션 기 능을 사용하여 수업 내용과 관련된 객관식 형식의 퀴즈를 작성 하여 중간마다 삽입하였다(Fig. 1A). 대부분의 퀴즈 문제는 복수 정답으로 구성되었으며, 오답 선지에는 피드백을 추가하였다. 이렇게 제작된 퀴즈 삽입형 동영상 강의를 본과 3학년 2학기 치 주과학 수업이 개설된 구글 클래스룸에 연동시켜 비동시적 온 라인 수업을 진행하였다(Fig. 1B). 퀴즈 시험 결과들은 구글 클 래스룸에 각각의 학생별로 자동으로 교수자에게 보고되었으며, 수업 내용 및 퀴즈와 관련된 질문이나 의견들은 구글 클래스룸 자체 댓글 기능을 통해 자유롭게 묻고 교수자에 의해 피드백되 었다.

\section{설문조사}

2020년 3학년 2학기 치주과학 수업이 종료된 후, 설문 동의 하에서 구글 클래스룸 플랫폼에서 구글 설문지 기능을 사용하 여 설문하였다(Fig. 2). 세 가지 강의방식에 대해 다음과 같이 크 게 7 가지 항목으로 나누어 조사하였다.

\section{딴짓(Other behaviors)}

'딴짓'은 강의를 수강하면서 학습과 관련 없는 행동을 의미하 였다[7]. 1점(전혀 하지 않는다)에서 5점(계속해서 한다)까지 5 점 척도로 설문하였으며, 점수가 높을수록 딴짓의 정도가 높음 을 의미하였다.

\section{강의몰입(Lecture flow)}

'강의몰입'이란 수업을 수강하는 학생들의 수업에 대한 몰입 정도를 의미하였다[7]. 1점(전혀 아니다)에서 5점(매우 그렇다) 까지 5점 척도로 설문하였으며, 점수가 높을수록 강의몰입이 높 음을 의미하였다. 


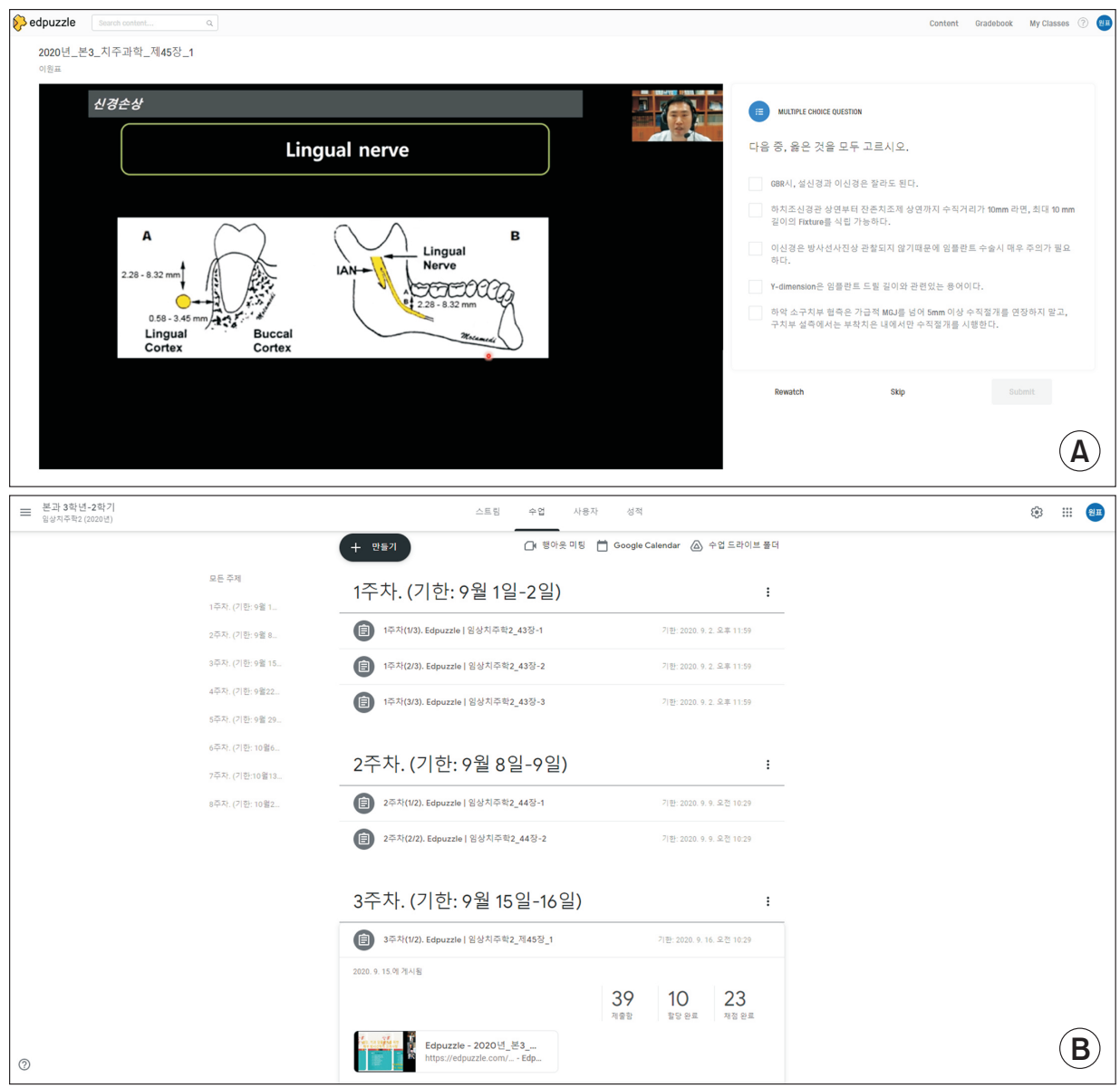

Fig. 1. (A) Video lecture with embedded multiple-choice quiz. (B) Video lecture with embedded quiz linked to the Google Classroom.

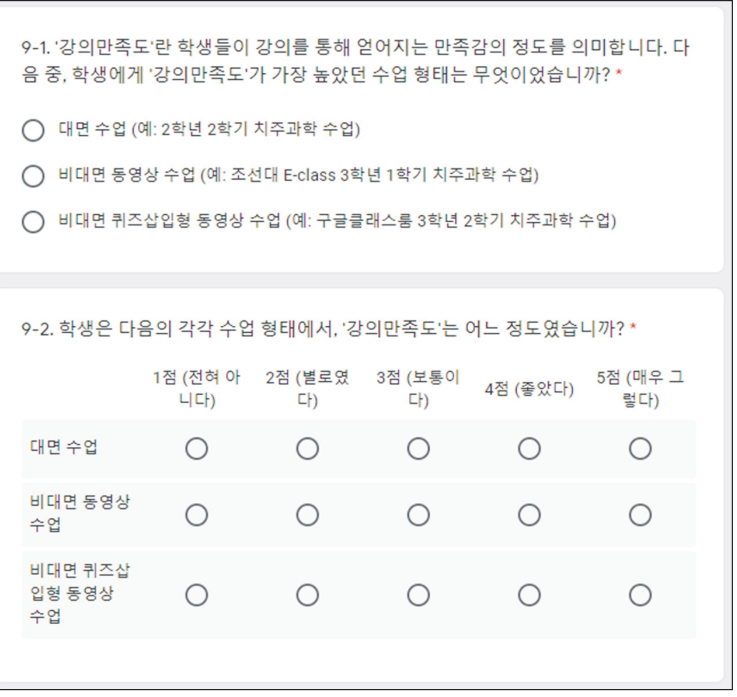

Fig. 2. Contents of questionnaires related to lecture satisfaction via Google Survey.

\section{학습동기(Learning motivation)}

'학습동기'란 학생으로 하여금 학습을 유발하고 학습을 유지 하도록 하는 마음가짐을 의미하였다[10]. 1점(매우 드물게)에서 5점(매우 자주)까지 5점 척도로 설문하였으며, 점수가 높을수록 학습동기가 높음을 의미하였다.

\section{학습자신감(Learning confidence)}

'학습자신감'이란 학생들이 자신의 학업적 수행능력에 대해 보이는 확신 또는 신념을 의미하였다[11]. 1점(전혀 그렇지 않 다)에서 5점(매우 그렇다)까지 5점 척도로 설문하였으며, 점수 가 높을수록 학습자신감이 높음을 의미하였다.

교수와의 커뮤니케이션(Communication with professor) [12]

1점(매우 낮다)에서 5점(매우 높다)까지 5점 척도로 설문하였 으며, 점수가 높을수록 교수와의 커뮤니케이션이 원활하였음을 의미하였다. 
동기와의 커뮤니케이션(Communication with students) [12]

1점(매우 낮다)에서 5점(매우 높다)까지 5점 척도로 설문하였 으며, 점수가 높을수록 동기와의 커뮤니케이션이 원활하였음을 의미하였다.

\section{강의 만족도(Lecture satisfaction)}

'강의 만족도'란 학생들이 강의를 통해 얻어지는 만족감의 정 도를 의미하였다[13]. 1점(전혀 아니다)에서 5점(매우 그렇다) 까지 5점 척도로 설문하였으며, 점수가 높을수록 강의 만족도가 높음을 의미하였다.

\section{통계분석}

각각의 범주형 변수들은 평균값과 표준편차로 표현했다. 각 그룹 간의 유의한 차이가 있는지 확인하기 위하여 비모수적 검 정방법인 Kruskal-Wallis 검정을 시행하였으며, 유의수준은 $p<0.05$ 로 설정하였다. Kruskal-Wallis 비모수 검정 후 사후 검정법으로 Bonferroni Correction Method (0.05/3=0.0167) 를 사용하였으며, 각 집단을 2개씩 묶어 Mann-Whitney 검정 을 실시하여 개별 집단간 유의성을 검정하였다. 통계학적 분석 은 SPSS version 22.0 for Windows (IBM Corp., Armonk, NY, USA)를 이용하였다.

\section{Results}

총 7가지 항목에 대해 각각 선호하는 강의방식(Table 1) 및 수 준(Fig. 3)은 다음과 같았다.

강의를 수강하는 중에 가장 딴짓을 많이 하게 되었던 강의방 식으로 총 70명의 치과대학 학생들 중 41명(59\%)이 퀴즈 삽입 이 없는 일반적인 동영상 강의를 활용한 비동시적 온라인 수업 을 들었다. 딴짓 정도는 평균 $2.8 \pm 1.0$ 점으로 대면 강의 $(2.3 \pm$
1.0점, $p=0.003)$ 및 퀴즈 삽입형 동영상 강의 $(2.1 \pm 0.8$ 점, $p<$ 0.001) 방식보다 유의하게 딴짓을 많이 하였다.

강의몰입 항목에 있어서는 40 명(57\%)의 학생들이 퀴즈 삽입 형 동영상 강의방식에서 가장 강의에 몰입할 수 있었다고 답하 였다. 또한, 강의 몰입 정도는 평균 $4.1 \pm 0.7$ 점으로 다른 두 가 지 강의방식(대면 강의: $p=0.004$, 일반적인 동영상 강의: $p<$ 0.001)보다 유의하게 몰입할 수 있었다. 하지만, 퀴즈 삽입이 없 는 일반적인 동영상 강의는 평균 $3.1 \pm 1.0$ 점으로 다른 강의방식 들(대면 강의: $p=0.001$ )보다 유의하게 가장 낮은 몰입정도를 보 였다.

학습동기 및 학습자신감 측면에서도 각각 42 명 $(60 \%)$ 및 44 명(63\%)의 학생들이 퀴즈 삽입형 동영상 강의방식을 가장 선호 한다고 답하였다. 또한, 각각 평균 4.1 \pm 0.7 점(대면 강의: $p<$ 0.001 , 일반적인 동영상 강의: $p<0.001$ ) 및 평균 $3.9 \pm 0.8$ 점 (대면 강의: $p<0.001$, 일반적인 동영상 강의: $p<0.001$ )으로 두 항목 모두에서 퀴즈 삽입형 동영상 강의방식이 다른 교육방 식들보다 유의하게 높은 수준을 보였다.

교수 및 동기와의 커뮤니케이션 항목에서는 각각 39명(56\%) 및 40 명 $(57 \%)$ 의 학생들이 모두 대면 강의 방식을 선호하였다. 퀴즈 삽입이 없는 일반적인 동영상 강의는 각각 평균 $2.7 \pm 1.1$ 점(대면 강의: $p<0.001$, 퀴즈 삽입형 동영상 강의: $p<0.001$ ) 및 2.9 \pm 1.0 점(대면 강의: $p<0.001$, 퀴즈 삽입형 동영상 강의: $p=0.001)$ 으로 두 항목 모두에서 유의하게 가장 낮은 의사소통 수준을 보였고, 대면 강의와 퀴즈 삽입형 동영상 강의방식 사이 (교수: $p=0.900$, 동기: $p=0.105$ )에서는 유의하지 않았다.

강의 만족도 측면에서는 45 명(64\%)의 치과대학생들이 퀴즈 삽입형 동영상 강의방식을 선호하였으며, 평균 $4.3 \pm 0.7$ 점으로 대면 강의(3.7 \pm 0.7 점, $p<0.001)$ 및 퀴즈 삽입이 없는 일반적 인 동영상 강의(3.4 \pm 1.0 점, $p<0.001)$ 보다 유의적으로 높은 수 준의 만족도를 보였다.

Table 1. Students' preferred lecture type of each survey question

\begin{tabular}{|c|c|c|c|}
\hline \multirow{2}{*}{ Survey question } & \multirow{2}{*}{ Offline } & \multicolumn{2}{|c|}{ Video lecture } \\
\hline & & No quiz & Embedded quiz \\
\hline Other behaviors & $15(21)$ & $41(59)$ & $14(20)$ \\
\hline Lecture flow & $23(33)$ & $7(10)$ & $40(57)$ \\
\hline Learning motivation & $20(29)$ & $8(11)$ & $42(60)$ \\
\hline Learning confidence & $15(21)$ & $11(16)$ & $44(63)$ \\
\hline Communication with professor & $39(56)$ & $5(7)$ & $26(37)$ \\
\hline Communication with students & $40(57)$ & $5(7)$ & $25(36)$ \\
\hline Lecture satisfaction & $14(20)$ & $11(14)$ & $45(64)$ \\
\hline
\end{tabular}

Values are presented as number (\%). 
A

Other behaviors

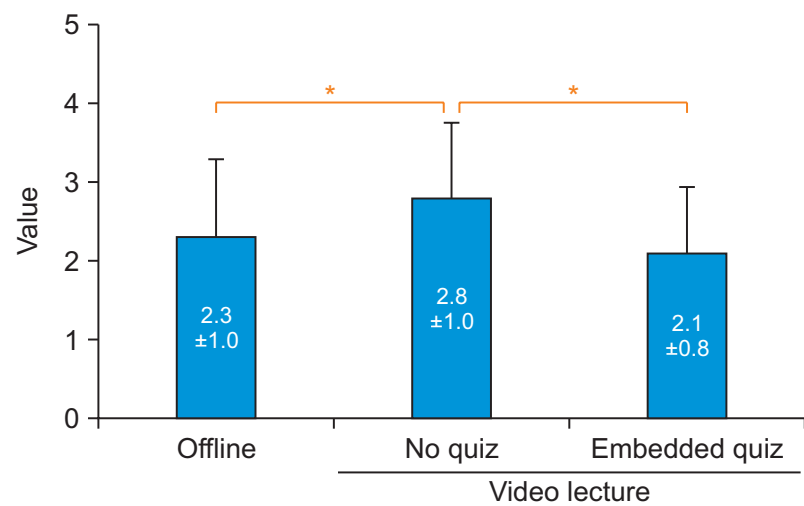

C

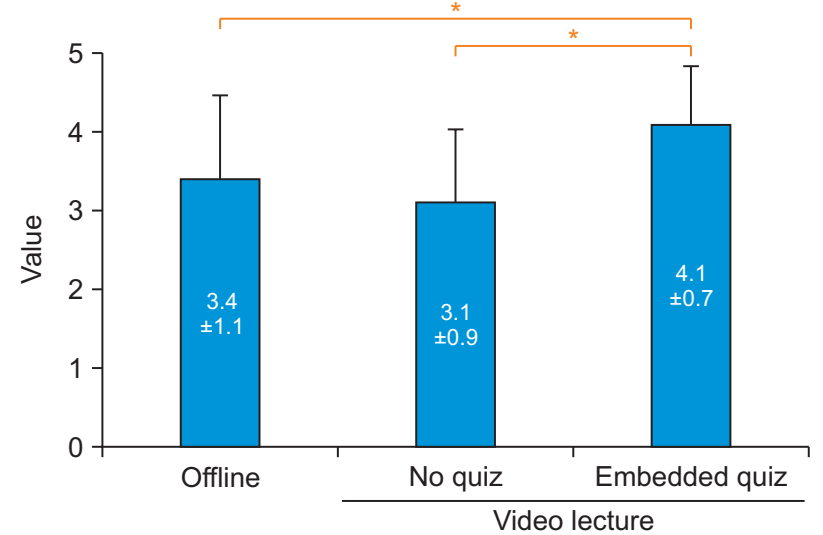

Fig. 3. Mean scores of each survey question.

${ }^{\star}$ Statistically significant difference $(p<0.05)$.

\section{Discussion}

본 연구에서 Edpuzzle 어플리케이션을 사용하여 만든 퀴즈 삽입형 동영상 강의를 활용한 비동시적 온라인 수업 방식이 전 통적인 대면 강의 및 일반적인 비대면 강의와 비교하여 치과대 학생들에게 어떻게 인식되고 있는지에 대해 알아보았다. 크게 7 가지 항목으로 구성된 설문조사 결과, 전반적으로 퀴즈 삽입 형 동영상 강의방식은 전통적인 대면 강의방식에 상응 또는 이 상의 교육효과가 있다고 치과대학생들에게 인식되고 있었으나, 퀴즈 삽입이 없는 일반적인 동영상 강의방식의 경우에는 대면 강의 방식보다 교육효과가 떨어졌다. 따라서, 본 연구는 사전 제 작된 동영상 강의에 단순히 퀴즈를 삽입하는 것만으로도 치과 대학생들에게 교육효과를 충분히 상승시킬 수 있음을 알 수 있 었다는 점에서 의의가 있다.

일반적인 동영상 강의방식의 경우 대면 강의 방식에 비해 학 생들은 학습과 관련 없는 행동들인 딴짓을 하게 될 가능성이 높
B

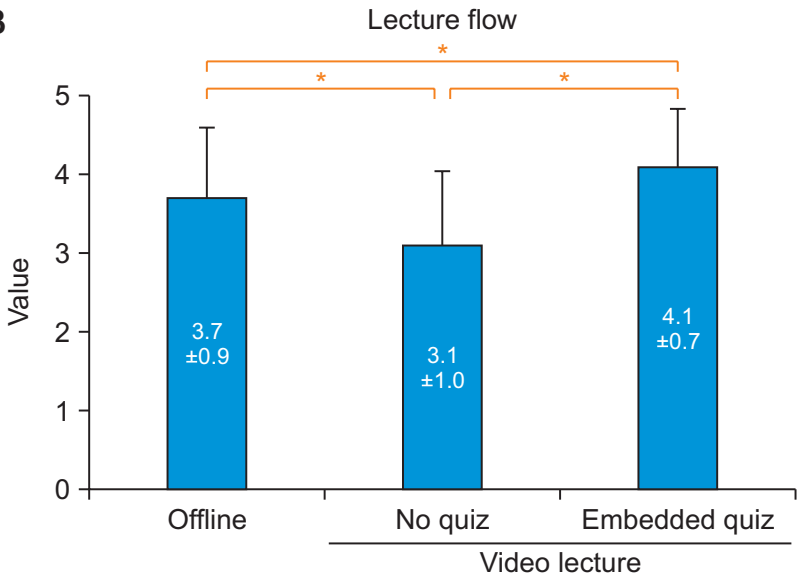

D

Learning confidence

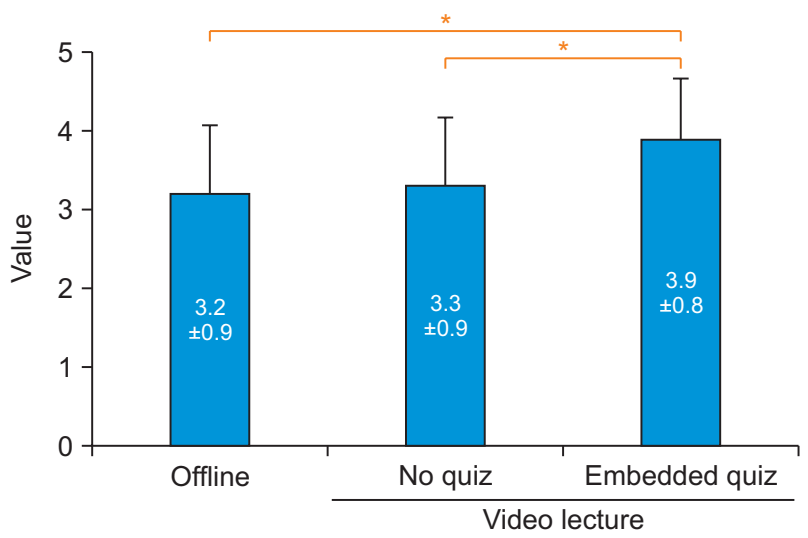

아지게 된다. 흥미로운 점은 젊은 세대일수록 동영상 강의를 수 강하면서 딴짓을 하는 경우에도 강의에 집중하고 있다고 느낀 다고 한다. 즉, 젊은 세대일수록 학생들이 멀티태스킹이 가능하 다고 느끼며 딴짓을 자연스러운 행동이라고 받아들인다. 문제 는 딴짓과 같은 행동들이 강의몰입에 부정적인 영향을 미칠 가 능성이 높다는 것이다[7]. 이번 연구에서도 3가지 교육방식 중, 퀴즈 삽입이 없는 일반적인 동영상 강의를 활용한 비동시적 온 라인 수업이 가장 딴짓을 하는 경향이 있었으며, 강의 몰입 측면 에서는 역으로 몰입도가 가장 낮았다. Choi 등[14]의 간호대학 생들을 대상으로 한 동영상 강의에서 딴짓에 영향을 미치는 요 인 분석 연구에서도 딴짓은 강의몰입과 유의한 강한 음의 상관 관계 $(\mathrm{r}=-24, p<0.001)$ 가 있음을 보고하였다.

이러한 일반적인 동영상 강의의 단점을 보완하기 위해 동영 상 강의 중간마다 퀴즈를 삽입한 경우 긍정적인 학습효과가 있 음이 보고되고 있다[15,16]. Jones 등[15]은 퀴즈 삽입형 동영상 강의를 수강한 학생들이 퀴즈 삽입이 없는 일반적인 동영상 강 


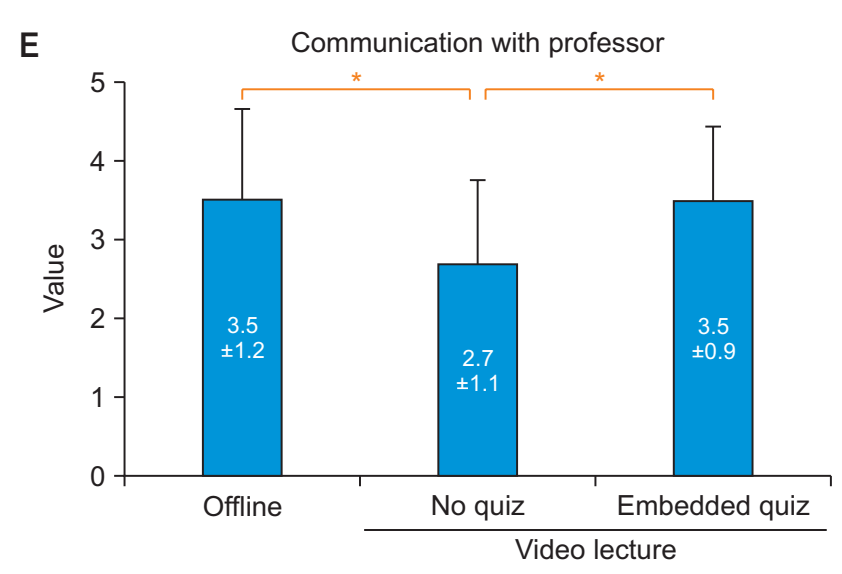

G

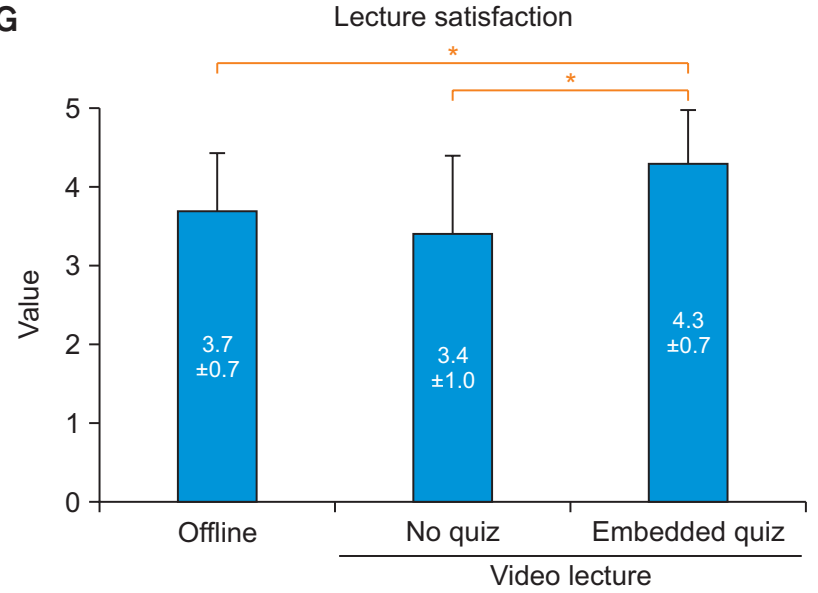

의를 수강한 학생들에 비해 비록 강의 후 치러진 시험결과에서 는 유의적인 차이가 없었지만, 퀴즈가 포함될 때 학생들은 동영 상 강의에 보다 더 몰입감을 느꼈으며 결과적으로 퀴즈 삽입형 동영상 강의를 선호한다고 보고하였다. Rice 등[16]의 연구에서 는 퀴즈 삽입형 동영상 강의에 대한 선호뿐만 아니라 시험결과 또한 유의적인 상승효과를 보고하였다. 이번 연구에서도 치과 대학생들은 학습동기, 학습자신감 및 강의 만족도 측면에서 다 른 교육방식들보다 퀴즈 삽입형 동영상 강의방식을 가장 선호 하는 경향이 관찰되었다.

퀴즈 삽입형 동영상 강의가 보다 더 효과적인 비대면 강의방 식이 되기 위해서는 몇 가지 주의 사항들이 있다. 먼저, 퀴즈 삽 입 위치가 동영상 강의가 다 끝난 마지막에 위치시키기보다는 중간중간 삽입 형태여야 보다 효과적이다. 또한, 퀴즈 내용이 딴 짓을 예방할 목적의 단순한 형태가 아니라 강의 내용의 연속선 상에 있어야 하며, 퀴즈 풀이 후 오답 및 정답 선지들에 대한 즉 각적인 피드백 내용이 포함되어야 한다[16]. 또한, 교수 및 동 기와의 커뮤니케이션 측면에서 보완이 필요하다. 이번 연구에 서 학생들은 여전히 의사소통 측면에서는 대면 강의를 가장 선 호하였으나 퀴즈 삽입형 동영상 강의방식과는 유의적인 차이

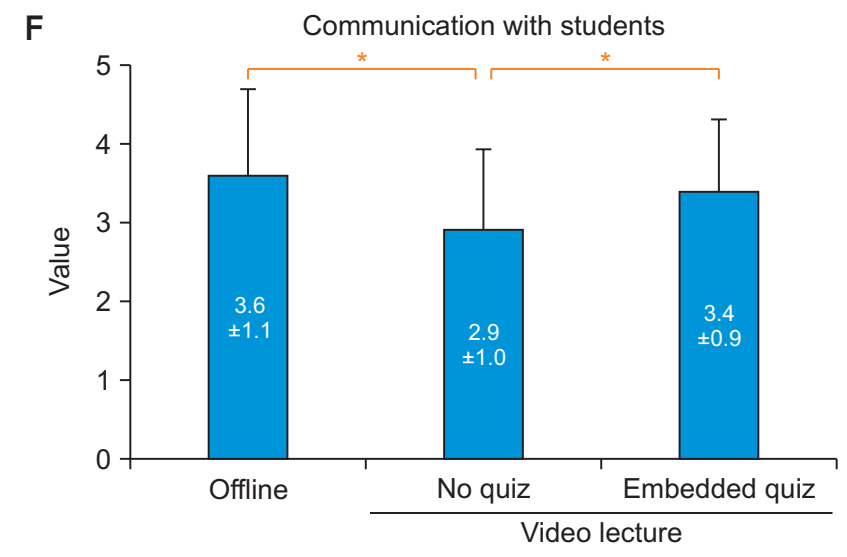

Fig. 3. Continued.

는 없었던 반면, 퀴즈 삽입이 없는 일반적인 동영상 강의방식이 유의적으로 가장 의사소통 측면에서 불편하다고 답하였다. 퀴 즈 삽입형 동영상 강의는 비대면 강의방식에서 의사소통을 위 한 하나의 해결방안인 댓글기능을 손쉽게 사용 가능한 구글 클 래스룸 플랫폼에 게시된 반면, 일반적인 동영상 강의는 댓글기 능이 없는 조선대학교 자체 LMS인 E-Class에 게시하였다. 따라 서, 동영상 강의물을 게시할 적절한 LMS 플랫폼 선택 또한 중요 하다.

이상의 연구 결과들을 종합해보면 퀴즈 삽입형 동영상 강의 를 활용한 비동시적 온라인 수업 방식이 치의학 교육에 있어 전 통적인 대면 수업의 효과적인 대안이 될 수 있다. 또한, 일반적 인 동영상 강의 중간중간에 퀴즈를 삽입하는 것이 치과대학생 들의 학습효과를 증진시킬 가능성이 있다. 이를 위해서는 적절 한 형식의 퀴즈 제작 및 LMS 플랫폼 선택 또한 중요하다. 하지 만, 이번 연구에서는 각 학기별 강의한 치주과학 수업 내용이 달 랐기 때문에, 향후에는 동일한 치주과학 수업 내용을 대상으로 다양한 수업 방식들이 학생들의 학습 효과에 미치는 연구 또한 필요하다. 또한, 앞으로 치주과학뿐만 아니라 다른 치의학 분야 에 대한 효과 검증을 위한 반복연구 및 학업성적과의 연관성 검 
증과 같은 후속연구들이 필요하리라 생각한다.

\section{Conflicts of Interest}

The authors declare that they have no competing interests.

\section{ORCID}

\author{
Won-Pyo Lee \\ https://orcid.org/0000-0003-1911-3454 \\ Joo-Hun Song \\ https://orcid.org/0000-0003-4229-6148
}

\section{References}

1. Daniel SJ. Education and the COVID-19 pandemic. Prospects (Paris) 2020;49:91-96. doi: 10.1007/s11125-02009464-3.

2. UNESCO. Education: from disruption to recovery [Internet]. Paris: UNESCO; 2019 [cited 2020 May 24]. Available from: https://en.unesco.org/covid19/educationresponse.

3. Ferrel MN, Ryan JJ. The impact of COVID-19 on medical education. Cureus 2020;12:e7492. doi: 10.7759/cureus. 7492 .

4. Sahu P. Closure of universities due to coronavirus disease 2019 (COVID-19): impact on education and mental health of students and academic staff. Cureus 2020;12:e7541. doi: 10.7759/cureus. 7541 .

5. Song HD, Kim KS. The development and application of an integrative assessment framework for analyzing interaction in asynchronous learning environments. J Korean HRD Res 2010;5:19-37.

6. Kang JH, Park MJ, Yun YJ, Choi HY, Park SW, Cho KS. Study on e-learner's attention improvements. J HCI Soc Korea 2014;2014:353-356.

7. Kim SY, Shin NM. A study on online learner's 'other be- haviors' and flow: comparing adolescents with adults. J Educ Inf Media 2019;25:273-298. doi: 10.15833/KAFEIAM.25.2.273.

8. Park ES, Woo YK, Cha JY, Park YH, Yun JY. A study of interaction usability to prevent breakaway while watching Elearning. J HCI Soc Korea 2018;2018:788-791.

9. Sotola LK, Crede M. Regarding class quizzes: a metaanalytic synthesis of studies on the relationship between frequent low-stakes testing and class performance. Educ Psychol Rev 2020 Aug 14 [Epub]. http://doi.org/10.1007/ s10648-020-09563-9.

10. Chang EH, Park SH. Effects of self-evaluation using smartphone recording on nursing students' competency in nursing skills, satisfaction, and learning motivations: focusing on foley catheterization. J Korean Acad Fundam Nurs 2017;24:118-127. doi: 10.7739/jkafn.2017.24.2.118.

11. Bandura A. Self-efficacy mechanism in human agency. Am Psychol 1982;37:122-147. doi: 10.1037/0003-066X.37.2. 122.

12. Kong JH, Moon HJ, Park JC. New trend of dental education: flipped learning for dental classes using Google classroom platform. J Digit Contents Soc 2016;17:317-327. doi: 10.9728/dcs.2016.17.5.317.

13. Jung EJ, Lee JD. The relationship between students' lecture satisfaction, positive self concept, and class attitude. J Korean Teach Educ 2016;33:447-465. doi: 10.24211/ tjkte.2016.33.2.447.

14. Choi EY, Yun JY, Park SY. Factors influencing the other behaviors taken by nursing student during online lectures. J Korea Converg Soc 2020;11:433-441. doi: 10.15207/JKCS. 2020.11.9.433.

15. Jones EP, Wahlquist AE, Hortman M, Wisniewski CS. Motivating students to engage in preparation for flipped classrooms by using embedded quizzes in pre-class videos. Inov Pharm 2021;12:6. doi: 10.24926/iip.v12i1.3353.

16. Rice P, Beeson P, Blackmore-Wright J. Evaluating the impact of a quiz question within an educational video. TechTrends 2019;63:522-532. doi: 10.1007/s11528-01900374-6. 